\title{
Contraceptive Use among Women who Inject Drugs: Motivators, Barriers, and Unmet Needs
}

\author{
Gitau Mburu ${ }^{1}$, James Ndimbii ${ }^{2}$, Sylvia Ayon ${ }^{2}$, Onesmus Mlewa ${ }^{2}$, Mike \\ Mbizvo $^{3}$, Cecilia Kihara ${ }^{4}$, Allan Ragi ${ }^{2}$
}

1. Division of Health Research, University of Lancaster, United Kingdom

2. Kenya AIDS NGO Consortium, Nairobi, Kenya

3. Population Council, Lusaka, Zambia

4. International HIV/AIDS Alliance, Brighton, United Kingdom

GM: g.mburu@lancs.ac.uk

JN: jndimbii@kanco.org

SA: sayon@kanco.org

OM: mkalama@kanco.org

MM:mmbizvo@popcouncil.org

CK: c.kihara@aidsalliance.org

AR: aragi@kanco.org

Correspondence should be sent to Gitau Mburu, Division of Health Research, University of Lancaster, LA1 4YW, United Kingdom. Email: g.mburu@lancs.ac.uk 


\begin{abstract}
We explored contraceptive use among 45 women who inject drugs in Coastal Kenya. Overall, $29 \%$ were using contraceptives, motivated by a fear of unplanned pregnancy, a desire to shield children from the difficulties of drug use, the need to prevent HIV and other sexually transmitted infections, encouragement from health providers and outreach workers, or because they had achieved the desired number of children. However, $69 \%$ were not using contraceptives. Barriers to use included: current pregnancy intentions, perceived infertility due to drug induced-amenorrhea, side-effects, intimate partners' influence, lack of information, complex healthcare appointments, and transport costs. Rights-based integration of sexual and reproductive health into harm reduction services for women who inject drugs is required to minimize unmet contraception needs.
\end{abstract}

Keywords: Reproductive health, drug abuse and dependence, contraception, Africa

People who inject drugs are a priority population for public health interventions, particularly HIV prevention. There are over 16 million people who inject drugs globally, of whom 3 million are infected with HIV (Mathers et al., 2008). Global health organizations recommend providing a package of harm reduction and HIV prevention interventions for all injecting drug users. This package includes needle and syringe exchange programs (NSPs), opioid substitution therapy with methadone (OST), and prevention and treatment of a range of infections including HIV, and other sexually and non-sexually transmitted infections (WHO, UNODC, \& UNAIDS, 2009).

Over the last few years, remarkable progress has been made in providing these services for people who use drugs globally (Degenhardt et al., 2014). However, significant coverage gaps persist, particularly in low and middle-income countries (Mathers et al., 2010). In particular, women who inject drugs are inequitably reached with harm reduction services (Page et al., 2015; Springer et al., 2015). There are an estimated 3.5 million women who inject drugs worldwide (Azim, Bontell, \& Strathdee, 2015; Des Jarlais, Feelemyer, Modi, 
Arasteh, \& Hagan, 2012), and a significant majority of them are of reproductive age.

However, compared to men, women who inject drugs are less likely to access drug treatment (Greenfield et al., 2007) and other health care services (Morrison, Ruben, \& Beeching, 1995). Many of them engage in sex work to support their own and their partners' drug use, often without adequate condom use (Azim et al., 2015). In addition, women who inject drugs experience worse drug use-related stigma than men do (Azim et al., 2015; Khuat, Morrow, Nguyen, \& Armstrong, 2015), especially when pregnant (Simpson \& McNulty, 2008), and, as a result, they have sub-optimal utilization of prenatal care (Peters et al., 2003).

Evidence suggests that most women who inject drugs, including those in harm reduction programs, often have unaddressed reproductive health needs (Black, Stephens, Haber, \& Lintzeris, 2012; Harding \& Ritchie, 2003; Morrison et al., 1995), including contraception (Black et al., 2012). Studies suggest that the broader reproductive health needs of women who inject drugs are often overlooked due to a narrow focus on HIV prevention (Sherman, Kamarulzaman, \& Spittal, 2008) and a failure to integrate wider health needs into drug treatment programs (Pinkham, Stoicescu, \& Myers, 2012). As a result, the unique needs of women who inject drugs, including sexual and reproductive health, are rarely responded to in harm reduction programs (Pinkham \& Malinowska-Sempruch, 2008; Pinkham et al., 2012; Tuchman, 2010).

However, understanding and addressing the sexual and reproductive health of this population is important at two levels. At a macro level, it is central to the achievement of universal access to reproductive health and gender equity, which in turn contributes to the achievement of sustainable development goals (UNODC, 2016) and the International Conference on Population and Development's (ICPD) recommendations (Cates \& Maggwa, 2014). At a micro level, understanding contraceptive needs, fertility-related behaviors, desired fertility, and other sexual and reproductive needs can inform women-centered 
services. The need for gender-sensitive services is currently gaining visibility, with calls to integrate interventions that address the unique needs and vulnerabilities of women in harm reduction services (Ayon et al., 2017; El-Bassel \& Strathdee, 2015; Ippoliti, Nanda, \& Wilcher, 2017; Iversen, Page, Madden, \& Maher, 2015; Pinkham \& Malinowska-Sempruch, 2008).

In Kenya, harm reduction and drug treatment services are nascent (Rhodes, Closson, Paparini, Guise, \& Strathdee, 2016): NSP and OST were incorporated within HIV and public health programs in 2013 (NASCOP, 2013). In this context, very few, if any, studies have been conducted on contraceptive use among women who inject drugs. However, information regarding contraception and other aspects of the sexual and reproductive health of women who inject drugs is particularly needed to inform facility- and community-based harmreduction service delivery models, many of which are in development (Ayon et al., 2017; Rhodes et al., 2016). Here, we report patterns of contraceptive use among women who inject drugs in Kenya.

\section{Method}

\section{Study Design}

Data reported here were generated as part of a large qualitative study whose aim was to explore the determinants of sexual and reproductive health among women who inject drugs. Specific objectives were to understand what the specific sexual and reproductive service needs of women who inject drugs are, and to explore determinants of access to sexual and reproductive health services in this population. Given the known complexity of the social contexts of women's drug use, contraception, and parenting (Olsen, Banwell, \& Madden, 2014), qualitative explorations are particularly well suited to illuminate different perspectives related to the intersection of women's drug use and reproduction. In the present study, we combined in-depth interviews (IDIs) and focus group discussions (FGDs) to gather 
complementary information (Esterberg, 2002) and triangulated these with IDIs with key stakeholders involved in service provision to drug users.

\section{Study Setting}

The study was conducted in two Kenyan coastal towns: Mombasa and Kilifi. In these towns, community-based services for injecting drug users were being implemented by the Kenya AIDS NGOs Consortium (KANCO), a local non-governmental organization. The services were being provided through two community-based organizations (CBOs): Reach out Centre Trust (REACH OUT) and the Muslim Education and Welfare Association (MEWA). Beginning in 2012, these sites formed part of a pilot implementation of a new community-based harm reduction service-delivery approach. As opposed to relying on drug users to attend health facilities, outreach workers contact injecting drug users in their own localities to provide them with services and referrals to drop-in centers or tertiary health facilities (Ayon et al., 2017; Coyle, Needle, \& Normand, 1998). The nature and scope of services provided to injecting drug users in the study context is shown in Table 1.

\section{Participants}

Participants were recruited via the above community-based organizations using convenience and purposive sampling strategies (Etikan, Musa, \& Alkassim, 2016; Robinson, 2014). Researchers (JN and SA) approached the organizations and explained the purpose of the study. Information sheets with detailed study information were provided to outreach teams, who then approached individual women during the course of their routine outreach and introduced them to the study. Those who were interested in taking part were screened for eligibility. To be included, participants had to be an adult aged at least 18 years, which is the legal age to provide independent consent; be aged 49 years or younger; and have a history of injecting drugs within the 90 days prior to participation in the study. Eligible participants were scheduled for IDI or FGDs. In addition to the women, a purposive sample of key 
stakeholders were selected based on their policy or service expertise, in consultation with the two community based organizations.

The final sample comprised of 45 women who injected drugs and five key stakeholders. Twenty-four of the women participated in IDIs (12 at each site), and 21 participated in three FGDs: one session in Mombasa $(n=5)$ and two sessions in Kilifi, $(n=6$ and $n=10$, respectively). The five key stakeholders, of whom three were female, included a community health worker $(n=1)$, outreach workers $(n=2)$, a Ministry of Health official $(n=1)$, and a CBO manager $(n=1)$. The age of the 45 women participants ranged from 19 to 56 years, with an average age of 28.5 years. Thirty-seven of the women had at least one child (range 15). The majority of women participants were single, without secondary or post-secondary education, and either unemployed or working in informal sector (See Table 2).

\section{Data Collection}

Data were collected in 2015 by two of the authors ( $\mathrm{NN}$ and SA) who are experienced in conducting qualitative research. All IDIs and FGDs were conducted in Swahili, the national language, or English, depending on participants' preferences. Data were collected in private rooms on the premises of the community-based organizations or in the offices of the key stakeholders. All IDIs and FGDs were audio recorded and lasted 45-60 minutes. At the end of the IDIs and FGDs, a brief, standardized set of questions was used to collect sociodemographic data, such as age, education, marital status, religion, source of income, fertility, contraceptive use, and current living arrangements.

\section{Data Analysis}

Socio-demographic data were entered into Excel files and descriptive summaries generated. IDIs and FGDs were transcribed into English as needed. All transcripts were imported into Nvivo v.11 (Bazeley, 2007), and analyzed through an inductive thematic approach (Bryman, 2012). Transcripts were read and used to generate nodes in Nvivo. Nodes 
were then populated with quotes from participants (Pope, Ziebland, \& Mays, 2000). Codes were then refined through the constant comparison approach (Silverman, 2001) and categorized to generate themes (Charmaz, 2000).

\section{Ethical Considerations}

Participation in this study was voluntary, and a written informed consent was obtained from each study participant after they were provided with a detailed description of the study's objectives and procedures. Data were collected in private rooms to safeguard confidentiality, and a token amount of Kenya Shillings (KES) 400 (the equivalent of four US dollars) was provided to participants. Ethical review and authorization for this research was provided by the National Commission for Science Technology and Innovation (NACOSTI).

\section{Results}

\section{Use of Contraceptives}

Thirteen women ( $29 \%$ of the overall sample) were currently using contraceptives at the time of the study. These included traditional methods such as periodic abstinence, and modern methods such as implants. Sixty-nine percent $(n=31)$ were not using contraception at the time of the study. Seven of the 13 women who were using contraceptives were sex workers, two were casual laborers or were involved in small businesses (e.g., kiosk or plaiting), and the remaining earned their income either through "hustling" $(n=2)$ or begging $(n=2)$. Six of the 31 women who were not using contraceptives were sex workers, 10 were either casual laborers or were involved in small businesses (e.g., kiosk or plaiting), four depended on their partners or spouses for income, and the remaining earned their income either through peddling $(n=3)$, "hustling" $(n=2)$, begging $(n=5)$, or as a peer-educator $(n=1)$. All of the six participants who reported relying on condoms were sex workers (See Table 3). 


\section{Motivations for Contraceptive Use}

The prospect of ideal motherhood and childrearing provided at least 10 women with an incentive to start using contraception. Narratives from the women who were using contraceptives indicated that they understood the responsibilities of motherhood and childrearing, and many believed that they could be capable parents, except for their drug use. It was clear that the fear of unplanned pregnancy motivated these women's contraceptive use, as exemplified by the following quote:

Life is hard, you can't get pregnant and be able to take care of the child when you are still a drug user. (Participant \# 5, Kilifi)

The above participant was one of the 37 women who already had a child. They said that, although they were in difficult circumstances, contraception allowed them to plan a pregnancy and fulfil their aspirations of motherhood:

So for me those are my reasons for family planning. When someone is ready, you just go and get it removed, then after 1 month you are good to have a baby, rather than have a baby that you are not expecting. (Participant \# 1, Kilifi)

In other cases, motivation for using contraception emanated from the fact that women had already achieved their desired fertility or family size. Asked about her decision to use injectable contraceptives, one participant remarked:

I am using the injection. I decided to on my own, because I have three children. I don't want to add a fourth one. The last one I was not expecting. (Participant \# 7, Kilifi)

As can be noted from the above excerpt, current use of contraceptives was often driven by past experiences of having conceived unexpectedly. In other cases, women were conscious of their social contexts and attempted to shield their children from the difficulties associated with drug use. At least 10 participants were cognizant that their ability to parent a child was 
threatened by economic hardships. In this context, their drug use was itself a primary motivator for contraceptive use:

I thought, 'hey, I have got all these children that I had not planned for, so I am better off having this implant so that I don't get a child that I will cause to suffer.'

(Participant \# 1, Kilifi)

Another incentive to use contraception was to prevent infections. Participants recognized the dual protection benefits of condoms related to both contraception and prevention of sexually transmitted infections (STIs). As a participant explained:

First of all, the condoms help a lot. They protect from gonorrhea and many infections All these means of family planning really help to prevent from unwanted babies and unplanned pregnancies. (Participant \# 1, Kilifi)

Another participant, who was living with HIV, suggested that she used condoms to prevent transmitting HIV infection to others and, at the same time, to prevent super-infection with other strains of the HIV virus. Asked about her motivations, she remarked:

To protect myself. So that I don't transmit my own and don't affect the others and stay with my own type of HIV virus. (Participant \# 11, Kilifi)

Given her emphasis on the benefit of condom use for preventing infections, she was questioned about whether this is the main use of condoms, to which she highlighted dual benefits "to protect against diseases and pregnancy" (Participant \# 11, Kilifi).

Another motivation of several participants living with HIV pertained to prevention of mother to child transmission of HIV. Asked about her reasons, one HIV-positive participant remarked that she was using contraceptives due to "this disease I am having. These days when you give birth you are told if you have it [HIV] you are to use a family planning method" (Participant \# 5, Kilifi). Attitudes toward contraception were intertwined with this participant's concern about her own health. Advice from health providers facilitated this 
participant's decision; she remarked that "according to the doctor...my immunity is still low" and, in her view, she was not in good health, and therefore chose to use contraceptives.

Another motivator for use of contraceptives was participants' interactions, acceptance or encouragement by facility-based health providers and outreach workers. Health providers particularly encouraged injecting drug users to use contraceptives. Women pointed out that they experienced positive attitude from health providers when they sought contraception compared to any other service. Asked about her experience and interaction with healthcare providers of contraception services at one of the referral hospitals, one respondent remarked:

They treat you well, because you have come to get family planning medications. They also encourage us to bring a friend along to get family planning services. (Participant \# 7, Kilifi).

Although findings suggested a bias towards providing contraception in particular, positive attitudes towards women were said to have resulted from training and sensitization of healthcare providers regarding the needs of women who inject drugs. Initially, interactions were said to have been negative because "the health care workers did not understand why and how they needed to serve female drug users" (Stakeholder \# 3, Kilifi). However, following training of healthcare providers, their interactions with women improved. Our data suggest that outreach workers play a mediatory role of sensitizing healthcare providers, especially when they accompanied women to health facilities:

If you say to the outreach worker: "How can I access family planning services?", they say: "Come tomorrow I'll take you the hospital." They don't leave us behind (Participant \# 10, Mombasa).

In these instances, a participant mentioned that it was outreach workers who "will be in front at the doctor". She elaborated that outreach worker would "talk" and explain their health needs to health providers (Participant \# 5, Kilifi). Indeed, narratives suggest that women first 
started using contraceptives as a result of interaction and information acquisition from outreach teams. Information from outreach workers was highly valued. One participant, who referred to the role of outreach teams specifically in shaping her decision to use contraceptives, said: "you know I was once a peer educator; they teach us" (Participant \# 6, Mombasa). In addition, a participant pointed out that "outreach workers usually give us condoms for our safety" (Participant \# 7, Mombasa). Although this condom provision might have been primarily driven by the need to prevent HIV, condoms were often used to prevent unwanted pregnancies as indicated in Table 3.

\section{Barriers to Use of Contraceptives}

Narratives from the eight women who did not have a child revealed deeply held aspirations of motherhood and desire for a future pregnancy. Yet, amidst the hope of achieving motherhood, virtually all of these women expressed disappointment that they could not conceive because of their ongoing drug use. One participant remarked:

I would want to have children, but I don't know what the problem is; is it my reproductive organs, or these drugs that I am using? (Participant \# 3, Kilifi)

However, majority of participants who were not using contraceptives had not made a deliberate choice, but were not using contraceptives due to a variety of reasons. Three women attributed their failure to use contraceptives - when they had intended to use them - either to forgetfulness, or to not being organized enough to follow-up on their appointments. Asked why she did not keep her appointments, one participant explained:

It is heroin; heroin causes all this. Even seeking for health services? ahh! I just keep thinking I'm alright. I don't even make follow-ups. (Participant \# 9, Kilifi)

Questioned further, this participant noted the apparent incompatibility of keeping appointments with ongoing drug use: "after stopping these drugs is when I can follow-up on services. Without stopping drugs, there is nothing I can follow-up on" (Participant \# 9, 
Kilifi). Forgetfulness was blamed for failure to keep appointments, as noted in the case of another participant:

I have a Norplant, but it requires to be removed this year. The card got lost, and I can't remember which month it is supposed to be removed. Now I see as if it is past the due date. (Participant \# 1, Kilifi)

Other barriers were related to the health system. For instance, when questioned further, the above participant's account suggested that strict scheduling of family planning services makes it impossible to access them:

I went last week... first they gave me a date that was the following day. On the day, I remembered when it was late, because when it gets to past 12 noon, they normally would have left, those people for 'Tupange' [family planning program]. Now they told me there is another date, so I'm now waiting for the next date, although I have not confirmed on what day it will be, but I will go there today to confirm. (Participant \# 1, Kilifi)

Transport costs were a contributing factor to low contraceptive use by these women. In the words of one, "getting time to go to other hospitals and use money for receive family planning services" prevented her use of contraceptives (Participant \# 9, Mombasa). Asked for her opinion about how family planning and other related services could be ideally provided to her and other persons who use drugs, another participant said that "first of all, they need to bring the service here because many women are lazy to go there [health facility]; sometimes they lack fare. It [family planning service] should be brought here to this drop-in center." (Participant \# 1, Kilifi)

Another reason for not using contraception was a perceived infertility due to amenorrhea. The potential of drug use to cause amenorrhea was central to women's attitudes toward contraception, as many speculated that their need for contraception was nullified by 
the amenorrhea. This belief reduced their uptake of most contraceptives, with the possible exception of condoms. Virtually all interviewed women had experienced amenorrhea associated with their drug use. When questioned about her experience of amenorrhea, one respondent commented that her lack of periods was "a result of using drugs" and stated that her drug use "has become my way of family planning, although I have not fully understood it" (Participant \# 3, Kilifi). It is not surprising that such participants determined that as long as they used drugs, they were unlikely to conceive:

Given the way in which I am using [drugs], I don't think that I will get pregnant any time soon. (Participant \# 3, Kilifi)

For at least two experienced users, drug-induced amenorrhea was the main method of managing potential conception. This was the case for one older woman, who had spaced her four children by varying her drug use pattern:

The drug makes one not to conceive, you see. If I inject a certain quantity of drug, I know I won't get pregnant. If I reduced to another particular quantity, I know I will get pregnant. That is how I do family planning. (Participant \# 9, Mombasa)

However, for the most part, amenorrhea caused frustration among participants who were planning to get pregnant:

I have stayed and stayed, and I have not gotten pregnant; I have gotten late, and I am not getting pregnant. I hear that when we use drugs, it is said that it usually prevents someone from getting pregnant...It usually prevents us from getting periods, and when you have periods you have very bad cramps, it is so painful. Other times it can take more than 2 years before you have periods. I don't know what it is usually happening. (Participant \# 8, Kilifi)

Interpretations of this phenomenon were diverse but often linked to infertility. For example, one women suggested that her "womanhood is so deeply located" apparently because "before 
I even conceived my first child, I waited for so long; I thought I was barren" (Participant \# 11, Kilifi). She elaborated further by stating that "I thought I was barren, I waited for so long. I left school, stayed with a man, left the man, stayed with another man, left again and I only came to conceive with the third man" (Participant \# 11, Kilifi).

Among those who had a history of contraceptive use, adverse side effects were a significant cause of concern and a barrier to the use of contraception, especially hormonebased methods. In an uncommon response, a participant voiced these concerns by mentioning that she was lucky not to have experienced adverse side effects. While "some makes your heart beat fast, and feel like vomiting. I am grateful this is working well with me; I don't have any complications" (Participant \# 7, Kilifi). Asked about her use of injectable contraceptives, another participant from Kilifi described experiencing "side effects such as difficulty in breathing, and weight gain" following which she "decided to leave them alone" (Participant \# 9, Kilifi).

Unfortunately, these side effects often made women not want to use any method at all, not even to switch to another method. One participant, responding to a question about her experience of raised blood pressure, stated that:

I was given an injection that brought complications. The medicine was changed and the next one also brought complications. I saw it would finish me very fast, so I left it. I totally stopped [family planning]. (Participant \# 9, Kilifi)

At least two other participants from Mombasa had stopped using the contraceptive pill and injectable contraceptives, respectively, due to menorrhagia. One remarked that "you know these pills also have side effects; you can you bleed the whole year"' (Participant \# 7, Mombasa), and the other said that "when I started injection for family planning, I was having periods throughout, so I stopped" (Participant \# 6, Mombasa). 
Influence by an intimate partner only rarely determined women's non-use of contraception. For instance, one participant remarked that "I was using a coil, and then my boyfriend said it was hurting him, and I was also having abdominal cramps. So I went and removed it" (Participant \# 10, Kilifi). More commonly, gender relations played out in condom use in the context of sex work. Here, inability to negotiate for condoms suppressed use of condoms because in the words of one participant, "there are other [clients] I have met they don't want a condom; 100\% they don't want condoms" (Participant \# 7, Kilifi).

Finally, although availability of information was a facilitator, the lack of it seemed to contribute directly to the low contraceptive use. Most women were only familiar with the contraceptives they were using, and most seemed unaware of the wide variety of contraception methods. For example, when asked which contraception methods she knew, one participant said that she did not know "because I don't use any" (Participant \# 12, Kilifi). Another participant responded that she was not using contraception because "I don't have the information about those things" (Participant \# 6, Mombasa) (See Table 4.)

\section{Unplanned Pregnancies and their Outcomes}

No participant described becoming pregnant while on contraception. However, given the range of barriers, it is not surprising that there were a number of unplanned pregnancies. Typical descriptions of these by participants were that they "got pregnant without planning" (Participant \# 7, Kilifi) or that they "had not intended, it was accidental" (Participant \# 11, Kilifi). A number of participants reported having conceived when they did not desire to become pregnant but had either not used contraceptives, or had missed taking them for some days. Some of them reported having realized they were pregnant quite late:

I discovered when I was already 5 months pregnant because I usually have irregular periods. I was just shocked to learn that I was pregnant, because I had only skipped a day without going for the injection. (Participant \# 10, Mombasa) 
Accounts from at least two women highlight the realities associated with unintended pregnancy. Upon realization that they were unexpectedly pregnant, some opted to carry the pregnancy to term, and others opted for abortion, with varied results. Within this context there were strong themes related to the influences of intimate partners on the potential termination of pregnancy:

After 3 months I got pregnant. You know we had not planned anything. I saw that he had changed. They made me to abort that pregnancy. (Participant \# 11, Kilifi) In other situations, women used herbal and other abortifacients, often unsuccessfully. One participant discussed how she had attempted unsuccessfully to terminate her pregnancy:

I was surprised that the pregnancy was already 4 months. I panicked and did not know what to do, so I smoked Bugizi and injected drugs. Then I thought she was dead. But she never died, here she is, growing up. (Participant \# 10, Mombasa)

\section{Discussion}

Understanding the contraceptive use and pregnancy intentions of women who inject drugs is critical in addressing unmet contraception needs, preventing unplanned pregnancies, and improving their health and that of their children. To our knowledge, this is the first study to assess contraceptive use among women who inject drugs in Kenya. Our study provides important findings related to the motivations, barriers, and potential unmet needs among this population, and the results highlight the highly contextual emotional, physiological, gender, and structural factors that affect decision making regarding fertility and pregnancy intentions. Several findings warrant policy and program attention.

The first concerns unmet contraceptive needs. Our participants reported several unplanned pregnancies, as well as abortions, which points to unmet contraception needs. Pregnancies ending in abortion are generally assumed to have been unintended (Santelli et al., 2003). These findings are in line with findings from a recent systematic review that 
reported high unmet contraceptive needs, especially for the most effective methods, among women who use drugs globally (Terplan, Hand, Hutchinson, Salisbury-Afshar, \& Heil, 2015). It is not surprising that women who use drugs are more likely than non-drug-using women to have unplanned pregnancies (Than et al., 2005).

In Kenya, contraceptive prevalence is around 47\% (Tumlinson, Pence, Curtis, Marshall, \& Speizer, 2015), which suggests a substantial level of unmet family planning needs among all women of reproductive age. Our results suggest that women who inject drugs may have an even higher level of unmet contraceptive need. The utilization of effective long-acting methods, such as intra-uterine devices (IUDs) and implants, was particularly limited. Studies from other countries have also shown very low prevalence of reliable contraception and high levels of unplanned pregnancies among women who inject opioid and other drugs (Heil et al., 2011; Ralph \& Spigner, 1986; Weber et al., 2003). Taken together with existing literature from other countries, our findings point to a substantial unmet contraception need in women who inject drugs at the Kenyan coast.

The second finding relates to the role of drug use in influencing contraception uptake. Although there was a desire to limit births among the majority of participants who already had children, participants recognized that their ability to parent a child was threatened by their drug use and social context, which was economically deprived. At the same time, drugs' association with amenorrhea and dysmenorrhea, a phenomenon well documented in international literature (Harding \& Ritchie, 2003; Olsen et al., 2014) was cited as a reason for not using contraception. In our study, participants frequently interpreted their amenorrhea or dysmenorrhea as infertility, as is the case in other contexts (Olsen et al., 2014). In sum, drug use was both a primary motivator and a barrier for contraceptive use.

Third, our data show that most women had made deliberate decisions regarding future pregnancy intentions, and they were trying to conceive or to prevent conception with valid 
reasons, which contradicts notions that women who inject drugs are unable to make logical decisions about their fertility. Similar observations were made by Olsen et al. (2014) who found that women drug users in Australia had high levels of agency, and made informed decisions regarding contraception, pregnancy and parenting. Additionally in our study, HIV positive women made deliberate attempts to use condoms consistently, similar to observations from other countries showing that HIV positive injecting drug users take into account the risk of HIV transmission in their contraceptive practices, and are often more likely than the general population to use male condoms (Vidal-Trecan et al., 2003).

The fourth finding relates to barriers to contraception uptake. Our data corroborate findings from other studies regarding the importance of a range of barriers, such as the infertility beliefs mentioned above (White, Phillips, Mulleady, \& Cupitt, 1993), contraception side effects (Harding \& Ritchie, 2003), transport costs, experiences with health care provision (Armstrong, Kenen, \& Samost, 1991), influence from intimate partners, forgetfulness, convenience (Egarter et al., 2013), influence from intimate partners, and difficulty negotiating condom use with sexual partners (Ippoliti et al., 2017; White et al., 1993). Most of these factors are not necessarily unique among women who inject drugs, as they are also observed among women who do not use drugs (Ippoliti et al., 2017; Peipert, Madden, Allsworth, \& Secura, 2012; Wulifan, Brenner, Jahn, \& De Allegri, 2016). However, some of these barriers may affect this population in a unique way. For instance, waiting in a queue for contraception can arguably be challenging for someone experiencing withdrawal symptoms, and, as noted in our study, some women simply left facilities when they sensed these symptoms. Although addressing all barriers is important, considering the unique nature of the challenges among women who use drugs will be essential to the success of potential interventions.

The fifth finding relates to the service model of providing contraception to women 
who inject drugs. Our study shows the value of an outreach approach for women who inject drugs in the study context, which is documented in depth elsewhere (Ayon et al., 2017). Apart from hospitals and peers, outreach workers were mentioned as a source of important information and referrals related to sexual and reproductive health, including contraception. Community-based outreach workers provided women with contraceptive pills and condoms. However, provision of long acting reversible contraceptives, such as IUDs and implants to drug users in their own localities was limited, and they had to be referred to specialized services by community-based outreach teams. Nevertheless, our findings suggest that integrating programs and interventions to prevent unintended pregnancies into outreachbased harm reduction programming is acceptable to women who inject drugs. Moving forward, women who inject drugs will need to be informed of all potential contraception options, and these methods must be brought closer to this population. Because uptake of contraception increases when more methods are available to potential users (Ross \& Stover, 2013), both community-based distribution and drop-in centers should be utilized to ensure that a wide range of contraceptives is made available. For instance, implants and IUDs could be provided at drop-in centers as part of harm reduction services.

Other researchers in countries with advanced responses to women who inject drugs have argued that offering contraception services in conjunction with substance use harm reduction programs is essential to reduce unintended pregnancy in this population (Black et al., 2012; Terplan et al., 2015). This requires a conscious expansion of the scope of harm reduction programs to include sexual and reproductive health services, especially for women (Malinowska-Sempruch, 2015; Morrison et al., 1995). As Black et al. (2012) argued, integrating these services could improve contraceptive uptake due to the familiar nonthreatening environment of harm reduction programs.

Ensuring that services are provided in spaces that women are familiar and 
comfortable with is particularly important given that attitudes of health providers affect women's access and uptake of sexual and reproductive health services (Armstrong et al., 1991; Ippoliti et al., 2017). In the areas where our study was conducted, the outreach program was expanded in 2014 to include sexual and reproductive health services, and this was accompanied by sensitization of health providers in facilities where referrals are made to mitigate stigmatizing attitudes towards women who inject drugs. Eliminating stigma and gender discrimination is a critical step toward achievement of the commitment contained in the ICPD Program of Action. Adopted in 1994 by 179 UN Member States, the ICPD Program of Action aims to advance the sexual and reproductive health and rights of all individuals (Barroso, 2014).

Finally, the confluence of drug use and sex work interfered with consistent use of condoms, which suggests that skills for condom negotiation would be useful, and it is important to recognize that sex work can occur in intoxicated states or alongside drug injecting. The promotion of dual method contraception use is particularly needed to mitigate the risk of HIV and other STIs. Although the risk of HIV among injecting drug users is not necessarily surprising, when considered in the context of unplanned pregnancies, it raises concerns related to child care and prevention of mother to child transmission. Women with unplanned pregnancies are less likely than those with intended pregnancies to seek antenatal care (Cheng, Schwarz, Douglas, \& Horon, 2009), and they are more likely to use drugs (Dott, Rasmussen, Hogue, \& Reefhuis, 2010). In addition, regardless of pregnancy intentions, mothers' preexisting physical and socioeconomic status has a significant impact on post-natal child health and well-being (Howell, Heiser, \& Harrington, 1999). Together, participants' socio-economic and HIV risk contexts suggest that avenues to increase condom use, including female condoms, should be explored regardless of their use of other contraceptives. At the same time, research should be done on the outcomes of children of women who inject 
drugs, as has been advocated by other researchers (Pinkham \& Malinowska-Sempruch, 2008).

\section{Limitations}

Before firm conclusions can be made, limitations of the present study should be noted. To begin, we did not plan to provide precise estimates of unmet contraceptive needs. However, our data show unmet needs and the context within which these needs occur. In addition, it is possible that social desirability bias influenced participants' comments. Finally, our study included participants who were in contact with an outreach-based harm reduction program, thus their healthcare seeking behaviors may differ with those without such contact (Coyle et al., 1998).

\section{Conclusion}

This article documents motivators, barriers, and unmet contraceptive needs among women who inject drugs at the Kenyan coast; our results add weight to global calls to advance the sexual and reproductive health and rights of all individuals, including women who inject drugs. Overall, $29 \%$ of women in this study were using contraceptives, motivated by a fear of unplanned pregnancy, desire to shield children from difficulties of drug use, prevention of HIV and sexually transmitted infections, encouragement from health providers and outreach workers, or having achieved the desired number of children. However, $69 \%$ were not using contraceptives, mainly due to current pregnancy intentions, perceived infertility from drug induced-amenorrhea, side-effects from contraceptives, intimate partners' influence, lack of information, complex healthcare appointments, and transport costs. Our participants reported unplanned pregnancies, as well as abortions, which suggests an unmet need of contraception.

These findings have practical implications and primarily suggest that integrating sexual and reproductive health services, including contraceptives, into drug-use treatment and 
other harm reduction services, is a feasible and acceptable approach to meeting the unique needs of women who inject drugs. Community-based distribution of contraceptives through outreach should be complemented with contraceptive services at both drop-in centers and conventional health facilities; and the ongoing sensitization of healthcare providers is also necessary. Although choice of approach may differ based on context and acceptability, it is essential to provide a wide range of contraceptive choice suitable to the preference and medical eligibility of each drug-using woman, within a rights-based approach.

\section{Acknowledgements}

Authors thank all study participants. This work was funded by the International HIV/AIDS Alliance, through its Innovation Fund.

\section{Disclosure statement}

No potential conflict of interest was reported by the authors.

\section{References}

Armstrong, K. A., Kenen, R., \& Samost, L. (1991). Barriers to family planning services among patients in drug treatment programs. Family Planning Perspectives, 23(6), 264-266, 270-261.

Ayon, S., Ndimbii, J., Jeneby, F., Abdulrahman, T., Mlewa, O., Wang, B., . . Mburu, G. (2017). Barriers and facilitators of access to HIV, harm reduction and sexual and reproductive health services by women who inject drugs: role of community-based outreach and drop-in centers. AIDS Care, Oct 25: 1-8. doi: 10.1080/09540121.09542017.01394965. [Epub ahead of print].

Azim, T., Bontell, I., \& Strathdee, S. A. (2015). Women, drugs and HIV. International Journal of Drug Policy, 26 Suppl 1, S16-21.

Barroso, C. (2014). Beyond Cairo: sexual and reproductive rights of young people in the new development agenda. Global Public Health, 9(6), 639-646.

Bazeley, P. (2007). Qualitative data analysis with NVIVO.London: Sage

Black, K. I., Stephens, C., Haber, P. S., \& Lintzeris, N. (2012). Unplanned pregnancy and contraceptive use in women attending drug treatment services. Australian and New Zealand Journal of Obstetrics and Gynaecology, 52(2), 146-150.

Bryman, A. (2012). Social Research Methods: Oxford: Oxford University Press.

Cates, W., Jr., \& Maggwa, B. (2014). Family planning since ICPD--how far have we progressed? Contraception, 90(6 Suppl), S14-21.

Charmaz, K. (2000). Grounded theory: Objectivist and constructivist methods. In Denzin N.K. \& Lincoln. Y.S. (Eds.), Handbook of Qualitative Research (pp. 509-535). Thousand Oaks, CA: Sage. 
Cheng, D., Schwarz, E. B., Douglas, E., \& Horon, I. (2009). Unintended pregnancy and associated maternal preconception, prenatal and postpartum behaviors. Contraception, 79(3), 194-198.

Coyle, S. L., Needle, R. H., \& Normand, J. (1998). Outreach-based HIV prevention for injecting drug users: a review of published outcome data. Public Health Reports, 113 Suppl 1, 19-30.

Degenhardt, L., Mathers, B., Wirtz, A. L., Wolfe, D., Kamarulzaman, A., Carrieri, M. P., . . Beyrer, C. (2014). What has been achieved in HIV prevention, treatment and care for people who inject drugs, 2010-2012? A review of the six highest burden countries. International Journal of Drug Policy, 25(1), 53-60.

Des Jarlais, D. C., Feelemyer, J. P., Modi, S. N., Arasteh, K., \& Hagan, H. (2012). Are females who inject drugs at higher risk for HIV infection than males who inject drugs: an international systematic review of high seroprevalence areas. Drug and Alcohol Dependence, 124(1-2), 95-107.

Dott, M., Rasmussen, S. A., Hogue, C. J., \& Reefhuis, J. (2010). Association between pregnancy intention and reproductive-health related behaviors before and after pregnancy recognition, National Birth Defects Prevention Study, 1997-2002. Maternal and Child Health Journal, 14(3), 373-381.

Egarter, C., Frey Tirri, B., Bitzer, J., Kaminskyy, V., Oddens, B. J., Prilepskaya, V., ... Weyers, S. (2013). Women's perceptions and reasons for choosing the pill, patch, or ring in the CHOICE study: a cross-sectional survey of contraceptive method selection after counseling. BMC Womens Health, 13, 9. doi:10.1186/1472-6874-13-9

El-Bassel, N., \& Strathdee, S. A. (2015). Women Who Use or Inject Drugs: An Action Agenda for Women-Specific, Multilevel, and Combination HIV Prevention and Research. Journal of Acquired Immune Deficiency Syndrome, 69 Suppl 2, S182-190.

Esterberg, K. (2002). Qualitative Methods in Social Research. Boston: USA McGraw-Hill. Etikan, I., Musa, S. A., \& Alkassim, R. S. (2016). Comparison of convenience sampling and purposive sampling. American Journal of Theoretical and Applied Statistics, 5(1), 1-4.

Greenfield, S. F., Brooks, A. J., Gordon, S. M., Green, C. A., Kropp, F., McHugh, R. K., . . Miele, G. M. (2007). Substance abuse treatment entry, retention, and outcome in women: a review of the literature. Drug and Alcohol Dependence, 86(1), 1-21.

Harding, C., \& Ritchie, J. (2003). Contraceptive practice of women with opiate addiction in a rural centre. Australian Journal of Rural Health, 11(1), 2-6.

Heil, S. H., Jones, H. E., Arria, A., Kaltenbach, K., Coyle, M., Fischer, G., . . Martin, P. R. (2011). Unintended pregnancy in opioid-abusing women. Journal of Substance Abuse Treatment, 40(2), 199-202.

Howell, E. M., Heiser, N., \& Harrington, M. (1999). A review of recent findings on substance abuse treatment for pregnant women. Journal of Substance Abuse Treatment, 16(3), 195-219.

Ippoliti, N. B., Nanda, G., \& Wilcher, R. (2017). Meeting the Reproductive Health Needs of Female Key Populations Affected by HIV in Low- and Middle-Income Countries: A Review of the Evidence. Studies in Family Planning, 48(2), 121-151.

Iversen, J., Page, K., Madden, A., \& Maher, L. (2015). HIV, HCV, and Health-Related Harms Among Women Who Inject Drugs: Implications for Prevention and Treatment. Journal of Acquired Immune Deficiency Syndromes, 69 Supp/ 2, S176-181.

Khuat, O. T., Morrow, M., Nguyen, T. N., \& Armstrong, G. (2015). Social context, diversity and risk among women who inject drugs in Vietnam: descriptive findings from a 
cross-sectional survey. Harm Reduction Journal, 12, 35. doi:10.1186/s12954-0150067-9

Malinowska-Sempruch, K. (2015). What interventions are needed for women and girls who use drugs? A global perspective. Journal of Acquired Immune Deficiency Syndromes, 69 Suppl 2, S96-97.

Mathers, B. M., Degenhardt, L., Ali, H., Wiessing, L., Hickman, M., Mattick, R. P., . . Strathdee, S. A. (2010). HIV prevention, treatment, and care services for people who inject drugs: a systematic review of global, regional, and national coverage. Lancet, 375(9719), 1014-1028.

Mathers, B. M., Degenhardt, L., Phillips, B., Wiessing, L., Hickman, M., Strathdee, S. A., . . Mattick, R. P. (2008). Global epidemiology of injecting drug use and HIV among people who inject drugs: a systematic review. Lancet, 372(9651), 1733-1745.

Morrison, C. L., Ruben, S. M., \& Beeching, N. J. (1995). Female sexual health problems in a drug dependency unit. International Journal of STD \& AIDS, 6(3), 201-203.

NASCOP. (2013). Kenya National Guidelines for the Comprehensive Management of the Health Risks and Consequences of Drug Use. Nairobi: National AIDS and STI Control Programme (NASCOP), Ministry of Health, Government of Kenya.

Olsen, A., Banwell, C., \& Madden, A. (2014). Contraception, punishment and women who use drugs. BMC Womens Health, 14, 5. doi:10.1186/1472-6874-14-5

Page, K., Tsui, J., Maher, L., Choopanya, K., Vanichseni, S., Mock, P. A., . . Martin, M. (2015). Biomedical HIV Prevention Including Pre-exposure Prophylaxis and Opiate Agonist Therapy for Women Who Inject Drugs: State of Research and Future Directions. Journal of Acquired Immune Deficiency Syndromes, 69 Suppl 2, S169-175.

Peipert, J. F., Madden, T., Allsworth, J. E., \& Secura, G. M. (2012). Preventing unintended pregnancies by providing no-cost contraception. Obstetrics and Gynecology, 120(6), 1291-1297.

Peters, V., Liu, K. L., Dominguez, K., Frederick, T., Melville, S., Hsu, H. W., . . Thomas, P. (2003). Missed opportunities for perinatal HIV prevention among HIV-exposed infants born 1996-2000, pediatric spectrum of HIV disease cohort. Pediatrics, 111(5 Pt 2), 1186-1191.

Pinkham, S., \& Malinowska-Sempruch, K. (2008). Women, harm reduction and HIV. Reproductive Health Matters, 16(31), 168-181.

Pinkham, S., Stoicescu, C., \& Myers, B. (2012). Developing effective health interventions for women who inject drugs: key areas and recommendations for program development and policy. Advances in Preventive Medicine, 2012, 269123. doi:10.1155/2012/269123.

Pope, C., Ziebland, S., \& Mays, N. (2000). Qualitative research in health care. Analysing qualitative data. British Medical Journal, 320(7227), 114-116.

Ralph, N., \& Spigner, C. (1986). Contraceptive practices among female heroin addicts. American Journal of Public Health, 76(8), 1016-1017.

Rhodes, T., Closson, E. F., Paparini, S., Guise, A., \& Strathdee, S. (2016). Towards "evidencemaking intervention" approaches in the social science of implementation science: The making of methadone in East Africa. International Journal of Drug Policy, 30, 1726.

Robinson, O. C. (2014). Sampling in Interview-Based Qualitative Research: A Theoretical and Practical Guide. Qualitative Research in Psychology, 11(1), 25-41. 
Ross, J., \& Stover, J. (2013). Use of modern contraception increases when more methods become available: analysis of evidence from 1982-2009. Global Health: Science and Practice, 1(2), 203-212.

Santelli, J., Rochat, R., Hatfield-Timajchy, K., Gilbert, B. C., Curtis, K., Cabral, R., . . . Schieve, L. (2003). The measurement and meaning of unintended pregnancy. Perspectives on Sexual and Reproductive Health, 35(2), 94-101.

Sherman, S. G., Kamarulzaman, A., \& Spittal, P. (2008). Women and drugs across the globe: a call to action. International Journal of Drug Policy, 19(2), 97-98.

Silverman, D. (2001). Interpreting qualitative data. Methods for analyzing talk text and interaction (2nd ed.). London: Sage.

Simpson, M., \& McNulty, J. (2008). Different needs: women's drug use and treatment in the UK. International Journal of Drug Policy, 19(2), 169-175.

Springer, S. A., Larney, S., Alam-Mehrjerdi, Z., Altice, F. L., Metzger, D., \& Shoptaw, S. (2015). Drug Treatment as HIV Prevention Among Women and Girls Who Inject Drugs From a Global Perspective: Progress, Gaps, and Future Directions. Journal of Acquired Immune Deficiency Syndromes, 69 Suppl 2, S155-161.

Terplan, M., Hand, D. J., Hutchinson, M., Salisbury-Afshar, E., \& Heil, S. H. (2015). Contraceptive use and method choice among women with opioid and other substance use disorders: A systematic review. Preventive Medicine, 80, 23-31.

Than, L. C., Honein, M. A., Watkins, M. L., Yoon, P. W., Daniel, K. L., \& Correa, A. (2005). Intent to become pregnant as a predictor of exposures during pregnancy: is there a relation? Journal of Reproductive Medicine, 50(6), 389-396.

Tuchman, E. (2010). Women and addiction: the importance of gender issues in substance abuse research. Journal of Addictive Diseases, 29(2), 127-138.

Tumlinson, K., Pence, B. W., Curtis, S. L., Marshall, S. W., \& Speizer, I. S. (2015). Quality of Care and Contraceptive Use in Urban Kenya. International Perspectives on Sexual and Reproductive Health, 41(2), 69-79.

UNODC. (2016). World Drug Report. Vienna, Austria: The United Nations Office on Drugs and Crime (UNODC), United Nations.

Vidal-Trecan, G., Warszawski, J., Coste, J., Bajos, N., Delamare, N., Grenier-Sennelier, C., \& Boissonnas, A. (2003). Contraceptive practices of non-HIV-seropositive injecting drug users. European Journal of Epidemiology, 18(9), 863-869.

Weber, A. E., Tyndall, M. W., Spittal, P. M., Li, K., Coulter, S., O'Shaughnessy, M. V., \& Schechter, M. T. (2003). High pregnancy rates and reproductive health indicators among female injection-drug users in Vancouver, Canada. European Journal of Contraception \& Reproductive Health Care, 8(1), 52-58.

White, D., Phillips, K., Mulleady, G., \& Cupitt, C. (1993). Sexual issues and condom use among injecting drug users. AIDS Care, 5(4), 427-437.

WHO, UNODC, \& UNAIDS. (2009). Technical Guide for Countries to Set Targets for Universal Access to HIV Prevention, Treatment and Care for Injecting Drug Users. Geneva, Switzerland: WHO, UNODC and UNAIDS.

Wulifan, J. K., Brenner, S., Jahn, A., \& De Allegri, M. (2016). A scoping review on determinants of unmet need for family planning among women of reproductive age in low and middle income countries. BMC Womens Health, 16, 2. doi:

10.1186/s12905-015-0281-3. 
Table 1. Services provided to women who inject drugs at the study sites

\begin{tabular}{|c|c|c|c|}
\hline Service domain & $\begin{array}{l}\text { Interventions and services } \\
\text { provided during outreach }\end{array}$ & $\begin{array}{l}\text { Interventions and } \\
\text { services provided at } \\
\text { drop-in centres }\end{array}$ & $\begin{array}{l}\text { Referrals to private and } \\
\text { government health and } \\
\text { social services }\end{array}$ \\
\hline $\begin{array}{l}\text { Prevention and } \\
\text { treatment of HIV } \\
\text { and co-infections }\end{array}$ & $\begin{array}{l}\text { Condoms, HIV testing, } \\
\text { information, communication } \\
\text { and education on HIV and } \\
\text { sexually transmitted } \\
\text { infections. }\end{array}$ & $\begin{array}{l}\text { HIV testing and } \\
\text { counselling. }\end{array}$ & $\begin{array}{l}\text { Referral for confirmation } \\
\text { and treatment of HIV, } \\
\text { and screening of Hepatitis } \\
\text { C and Tuberculosis. }\end{array}$ \\
\hline Harm reduction & $\begin{array}{l}\text { Clean needle and syringes, } \\
\text { alcohol swabs, cotton wool. }\end{array}$ & $\begin{array}{l}\text { Addiction counseling and } \\
\text { first aid for violence and } \\
\text { overdose. }\end{array}$ & $\begin{array}{l}\text { Referrals for medically } \\
\text { assisted therapy with } \\
\text { methadone. }\end{array}$ \\
\hline $\begin{array}{l}\text { Sexual and } \\
\text { reproductive } \\
\text { health services }\end{array}$ & $\begin{array}{l}\text { Information on family } \\
\text { planning, sister-to-sister } \\
\text { counselling, hygiene } \\
\text { packages/tampons and oral } \\
\text { contraceptive pills. }\end{array}$ & $\begin{array}{l}\text { Pre-natal education, and } \\
\text { provision of short-acting } \\
\text { reversible contraceptives. }\end{array}$ & $\begin{array}{l}\text { Referral for long-acting } \\
\text { long-acting reversible } \\
\text { contraception, ante-natal } \\
\text { care, and screening for } \\
\text { cervical cancer. }\end{array}$ \\
\hline $\begin{array}{l}\text { Personal, social } \\
\text { and child care } \\
\text { services }\end{array}$ & $\begin{array}{l}\text { Transportation to health } \\
\text { facilities and provision of } \\
\text { personal care items. }\end{array}$ & $\begin{array}{l}\text { Personal care (shower, } \\
\text { toothbrush/paste, lotion), } \\
\text { short-term shelter, and } \\
\text { diapers for children. }\end{array}$ & $\begin{array}{l}\text { Referrals for sexual } \\
\text { violence and legal } \\
\text { assistance. }\end{array}$ \\
\hline
\end{tabular}


Table 2. Participant characteristics

\begin{tabular}{|c|c|c|c|c|}
\hline Characteristic & IDI $(n=24)$ & $\begin{array}{l}\text { FGDs } \\
(n=21)\end{array}$ & $\begin{array}{c}\text { Total } \\
(n=45)\end{array}$ & $\%$ \\
\hline Age mean years, (SD) & $26.4(7.3)$ & $30.5(5.8)$ & $28.4(8.5)$ & \\
\hline Number of children, mean (SD) & $1.5(1.4)$ & $1.9(1.2)$ & $1.6(1.33)$ & 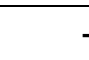 \\
\hline \multicolumn{5}{|l|}{ Education } \\
\hline None & 4 & 4 & 8 & $18 \%$ \\
\hline Primary & 13 & 10 & 23 & $51 \%$ \\
\hline Secondary & 6 & 6 & 12 & $27 \%$ \\
\hline Post-secondary & 0 & 1 & 1 & $2 \%$ \\
\hline Unknown & 1 & 0 & 1 & $2 \%$ \\
\hline \multicolumn{5}{|l|}{ Marital status } \\
\hline Married & 5 & 3 & 8 & $18 \%$ \\
\hline Live in partner & 7 & 5 & 12 & $27 \%$ \\
\hline Single & 11 & 13 & 24 & $53 \%$ \\
\hline Unknown & 1 & 0 & 1 & $2 \%$ \\
\hline \multicolumn{5}{|l|}{ Income source } \\
\hline Casual labor & 2 & 5 & 7 & $16 \%$ \\
\hline Food Kiosk/plaiting & 3 & 2 & 5 & $11 \%$ \\
\hline Sex work & 9 & 4 & 13 & $29 \%$ \\
\hline Peddling & 1 & 2 & 3 & $7 \%$ \\
\hline Peer educator & 0 & 1 & 1 & $2 \%$ \\
\hline Family or partner & 8 & 1 & 4 & $9 \%$ \\
\hline Begging, hustling & 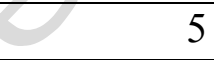 & 6 & 11 & $24 \%$ \\
\hline Unknown & 1 & 0 & 1 & $2 \%$ \\
\hline \multicolumn{5}{|l|}{ Drug use } \\
\hline $\begin{array}{l}\text { Duration using drugs, mean years } \\
\text { (SD) }\end{array}$ & $7.8(4.9)$ & $9.1(6.3)$ & $8.5(5.6)$ & 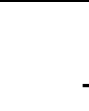 \\
\hline Duration injecting, mean years (SD) & $3.3(2.6)$ & $2.0(2.0)$ & $2.6(2.5)$ & - \\
\hline \multicolumn{5}{|l|}{ Main drugs used } \\
\hline Heroin & 11 & 1 & 12 & $27 \%$ \\
\hline Heroin, and other drugs & 11 & 15 & 26 & $58 \%$ \\
\hline Cocaine & 1 & 3 & 4 & $9 \%$ \\
\hline Cocaine and other drugs & 1 & 2 & 3 & $6 \%$ \\
\hline
\end{tabular}

Abbreviations: $\mathrm{SD}=$ standard deviation. 
Table 3. Current contraceptive use among study participants

\begin{tabular}{lcccc}
\hline Contraceptive & $\begin{array}{c}\text { IDI } \\
(\mathbf{n = 2 4})\end{array}$ & $\begin{array}{c}\text { FGDs } \\
(\mathbf{n = 2 1})\end{array}$ & $\begin{array}{c}\text { Total } \\
(\mathbf{n = 4 5})\end{array}$ & $\%$ \\
\hline Condoms & 5 & 1 & 6 & $13 \%$ \\
Calendar & 1 & 0 & 1 & $2 \%$ \\
Implant & 2 & 0 & 2 & $4 \%$ \\
Herbal & 1 & 0 & 1 & $2 \%$ \\
None & 13 & 18 & 31 & $69 \%$ \\
Injection & 1 & 2 & 3 & $7 \%$ \\
Unknown & 1 & 0 & 1 & $2 \%$ \\
\hline
\end{tabular}


Table 4. Motivators and barriers of contraceptive use among study participants

\begin{tabular}{|c|c|c|c|}
\hline $\begin{array}{l}\text { Major } \\
\text { themes }\end{array}$ & $\begin{array}{l}\text { Minor } \\
\text { themes }\end{array}$ & Codes & Illustrative quote \\
\hline \multirow{6}{*}{ Motivators } & \multirow[t]{2}{*}{$\begin{array}{l}\text { Planned } \\
\text { motherhood }\end{array}$} & $\begin{array}{l}\text { To prevent suffering of } \\
\text { their child }\end{array}$ & $\begin{array}{l}\text { If I get pregnant I cannot accept to } \\
\text { give birth. The way I suffered with } \\
\text { my children? (Participant } \# 1 \text {, Kilifi). }\end{array}$ \\
\hline & & $\begin{array}{l}\text { Future pregnancy } \\
\text { intentions }\end{array}$ & $\begin{array}{l}\text { Because children should be planned, } \\
\text { because you are not supposed to } \\
\text { come to earth to suffer, it is very sad } \\
\text { (Participant \# } 1 \text {, Kilifi). }\end{array}$ \\
\hline & $\begin{array}{l}\text { Interest in own } \\
\text { health }\end{array}$ & $\begin{array}{l}\text { Perception of own } \\
\text { health while using drugs }\end{array}$ & $\begin{array}{l}\text { You can't get pregnant and then take } \\
\text { care of the child when you are still } \\
\text { smoking, you wouldn't have enough } \\
\text { energy so you have to protect your } \\
\text { health (Participant \# 5, Kilifi). }\end{array}$ \\
\hline & \multirow[t]{2}{*}{$\begin{array}{l}\text { To prevent HIV } \\
\text { and STIs }\end{array}$} & $\begin{array}{l}\text { To prevent HIV } \\
\text { transmission to unborn } \\
\text { child }\end{array}$ & $\begin{array}{l}\text { If you have [HIV]... you are asked } \\
\text { which method you want, and you are } \\
\text { then given there and then (Participant } \\
\# 5 \text {, Kilifi). }\end{array}$ \\
\hline & & $\begin{array}{l}\text { To prevent acquisition } \\
\text { of other diseases }\end{array}$ & $\begin{array}{l}\text { I am using it to protect from diseases } \\
\text { and pregnancy (Participant \# 11, } \\
\text { Kilifi) }\end{array}$ \\
\hline & $\begin{array}{l}\text { Availability of } \\
\text { information }\end{array}$ & $\begin{array}{l}\text { Peers and outreach as } \\
\text { sources of information }\end{array}$ & $\begin{array}{l}\text { They are helping us with condoms, } \\
\text { and they educate us sometimes } \\
\text { (Participant \# 7, Mombasa). }\end{array}$ \\
\hline \multirow{7}{*}{ Barriers } & $\begin{array}{l}\text { Lack of } \\
\text { information }\end{array}$ & Low aware & $\begin{array}{l}\text { Family planning? Those things I } \\
\text { don't know (Participant \# 1, } \\
\text { Mombasa). }\end{array}$ \\
\hline & & Influence by partner & $\begin{array}{l}\text { I have a husband... he hasn't allowed } \\
\text { me to use, because he is not satisfied } \\
\text { with one baby (Participant } \# 8 \text {, } \\
\text { Kilifi). }\end{array}$ \\
\hline & $\begin{array}{l}\text { Motherhood } \\
\text { aspirations }\end{array}$ & $\begin{array}{l}\text { Own desire to get } \\
\text { pregnant }\end{array}$ & $\begin{array}{l}\text { I am in relationship that I would have } \\
\text { liked to have a child so at the } \\
\text { moment I am not using any method } \\
\text { of prevention (Participant \# } 7 \text {, } \\
\text { Mombasa). }\end{array}$ \\
\hline & Side effects & Side effects & $\begin{array}{l}\text { Blood pressure came up, then I was } \\
\text { told it doesn't befit me (Participant \# } \\
9 \text {, Kilifi). }\end{array}$ \\
\hline & $\begin{array}{l}\text { Perceived } \\
\text { infertility }\end{array}$ & $\begin{array}{l}\text { Amenorrhea/ } \\
\text { dysmenorrhea }\end{array}$ & $\begin{array}{l}\text { I haven't yet got pregnant with him; I } \\
\text { don't know what it is (Participant \# } \\
4 \text {, Mombasa). }\end{array}$ \\
\hline & \multirow[b]{2}{*}{$\begin{array}{l}\text { Convenience } \\
\text { and cost of } \\
\text { health services }\end{array}$} & Delay in health services & $\begin{array}{l}\text { Since I had "arosto" [ withdrawal] } \\
\text { and could not queue, I just left } \\
\text { (Participant \# 10, Mombasa). }\end{array}$ \\
\hline & & Cost & $\begin{array}{l}\text { There is a time we lack the condoms } \\
\text { that are given for free, you are forced } \\
\text { to buy if you have money to buy }\end{array}$ \\
\hline
\end{tabular}


(Participant \# 8 Mombasa). 